\title{
The utility of terrestrial photogrammetry for assessment of tree volume and taper in boreal mixedwood forests
}

\author{
Christopher Mulverhill ${ }^{1}$ (D) Nicholas C. Coops ${ }^{1} \cdot$ Piotr Tompalski $^{1} \cdot$ Christopher W. Bater $^{2} \cdot$ Adam R. Dick $^{3}$
}

Received: 23 January 2019 / Accepted: 9 June 2019 / Published online: 8 August 2019

(C) The Author(s) 2019

\begin{abstract}
- Key Message This study showed that digital terrestrial photogrammetry is able to produce accurate estimates of stem volume and diameter across a range of species and tree sizes that showed strong correspondence when compared with traditional inventory techniques. This paper demonstrates the utility of the technology for characterizing trees in complex habitats such as boreal mixedwood forests.

- Context Accurate knowledge of tree stem taper and volume are key components of forest inventories to manage and study forest resources. Recent developments have seen the increasing use of ground-based point clouds, including from digital terrestrial photogrammetry (DTP), to provide accurate estimates of these key forest attributes.

- Aims In this study, we evaluated the utility of DTP based on a small set of photos (12 per tree) for estimating stem volume and taper on a set of 15 trees from 6 different species (Populus tremuloides, Picea glauca, Pinus contorta latifolia, Betula papyrifera, Picea mariana, Abies balsamea) in a boreal mixedwood forest in Alberta, Canada.

- Methods We constructed accurate photogrammetric point clouds and derived taper and volume from three point cloud-based methods, which were then compared with estimates from conventional, field-based measurements. All methods were evaluated for their accuracy based on field-measured taper and volume of felled trees.

- Results Of the methods tested, we found that the point cloud-derived diameters in a taper curve matching approach performed the best at estimating diameters at the lowest parts of the stem $(<30 \%$ of total tree height), while using known DBH and height provided more accurate estimates for the upper parts of the stem ( $>50 \%$ of total height). Using the field-measured DBH and height as inputs to calculate stem volume yielded the most accurate predictions; however, these were not significantly different from the best point cloud-based estimates.

- Conclusion The methodology confirmed that using a small set of photographs provided accurate estimates of individual tree $\mathrm{DBH}$, taper, and volume across a range of species and size gradients $(10.8-40.4 \mathrm{~cm} \mathrm{DBH})$.
\end{abstract}

Keywords Photogrammetry $\cdot$ Forest inventory $\cdot$ Taper $\cdot$ Volume $\cdot$ Point cloud

Handling Editor: David Drew

Contribution of the co-authors Conceptualization: all; methodology: CM, NCC, PT, CWB; formal analysis: CM, NCC, and PT; resources: all; writing: all; funding acquisition: NCC and CWB.

This article is part of the Topical Collection on Frontiers in Modelling Future Forest Growth Yield and Wood Properties

Christopher Mulverhill

cmulv@mail.ubc.ca

1 Faculty of Forestry, University of British Columbia, 2424 Main Mall, Vancouver, BC V6T 1Z4, Canada

2 Forest Management Branch, Forestry Division, Alberta Agriculture and Forestry, Edmonton, Alberta T5K 2M4, Canada

3 Canadian Wood Fibre Centre, 1350 Regent Street, P.O. Box 4000, Fredericton, New Brunswick E3B 5P7, Canada

\section{Introduction}

The key to sustainably managing the world's 4 billion hectares of forested area (Bahamondez et al. 2010) is undertaking detailed and accurate inventories at varying scales (Gillis et al. 2005). Forest inventories are carried out at both operational and strategic levels, providing insight to shortterm harvesting strategies or long-term environmental management, respectively (Wulder et al. 2008). The development of inventory techniques to provide robust and reliable information is critical for forest practitioners to understand dynamic forest ecosystems in changing and uncertain environmental conditions. This is particularly important in the boreal mixedwood, which represents a major component of forest habitat in the northern hemisphere, 
and whose structural and compositional diversity make it resilient to a variety of disturbances (Chen and Popadiouk 2002).

While some components of a forest inventory are distribution-based, such as species mixtures and age, the size of individual tree stems remains a critical measurement that provides the basis for the remainder of a forest inventory. One such measurement is the diameter at breast height (DBH), which is a key input to allometric equations calculating, for example, volume (Huang 1994) or biomass (Lambert et al. 2005). A relative frequency distribution of $\mathrm{DBHs}$ in a given area yields a stem size distribution (Taubert et al. 2013), which can be used directly to estimate forest attributes such as its structure, successional stage, or volume (Gobakken and Næsset 2004; Hetemäki et al. 2010; Nduwayezu et al. 2015). These inventory attributes provide valuable insights to inform stand- and landscape-level forest management decisions; therefore, their complete and accurate estimation is critical for maximizing a range of both economic and ecological forest values.

Many forest inventory attributes are manually measured as a part of a ground-based inventory, where all, or a sample, of the trees above a given diameter threshold in a sample area are measured. However, traditional inventory methods of measuring tree stem taper is difficult and typically requires felling the tree. Additionally, for trees with unconventional stem shapes resulting from varying growth patterns or environmental conditions, traditional groundbased inventory methods and equations based on diameter and height as inputs may fail to provide accurate estimates of tree volume or biomass.

In order to meet increasing demands of data accuracy and robustness, recent years have seen the incorporation of remote-sensing technologies to enhance forest inventories (White et al. 2016; Leckie and Gillis 1995; Wulder and Franklin 2003). One such technology is Terrestrial Laser Scanning (TLS), which uses Light Detection and Ranging, or LiDAR, from a ground-based sensor to more effectively characterize individual stems at a plot or individual tree scale, providing accurate estimates of tree DBH, height, stem volume, and stem biomass (Liang et al. 2016). However, TLS units are expensive and often unwieldy (Eitel et al. 2013). A faster and inexpensive alternative to derive similar data for use in forest inventory is digital photogrammetry, which creates point clouds using images taken at multiple locations. Photogrammetric point clouds derived from airborne imagery, called digital aerial photogrammetry (DAP), are used to create highly detailed surface models of the forest canopy at broad scales, but typically cannot return points from under the surface of the canopy (Tao et al. 2011; White et al. 2015). Photogrammetric point clouds can also be derived from ground-based imagery, covering a smaller area than that of DAP, but providing a much higher level of detail at the individual tree level. Recent research has shown the success of digital terrestrial photogrammetry (DTP) in the reconstruction of individual trees for attributes such as DBH (Forsman et al. 2016), location within a plot (Liang et al. 2014a), and stem shape (Bauwens et al. 2017).

Despite advancements in DTP technology and associated methods, there are current limits to its operational use. The need for manual intervention or trial and error in point cloud generation has limited the application of DTP within forest management and ecological modeling, with advances in automation of point cloud generation, an important way forward for making the technology useful as an operational tool (Mikita et al. 2016; Berveglieri et al. 2014; Hapca et al. 2007). Additionally, previous studies using DTP have relied on either the acquisition of hundreds to thousands of images over a given area (Mokroš et al. 2018), or tens to hundreds of images of single trees (Bauwens et al. 2017; Miller et al. 2015), thereby raising issues of time or data storage requirements in operational capacities. Point cloud-derived upper stem measurements, such as those from Fang and Strimbu (2017), could provide better estimates of attributes such as taper, volume, or biomass (Bauwens et al. 2017). However, most studies focus on relatively even-sized stands or a single primary species (Fang and Strimbu 2017), and, as a result, an additional analysis of point cloud accuracy across species and environmental gradients is needed to understand the utility of DTP in irregular stands such as those present in boreal mixedwood forests.

In this study, we evaluate a methodology for DTP estimation of DBH, upper stem diameter (>1.3 m), and volume of individual trees in a boreal mixedwood forest. Limited sets of photographs taken at known locations were used to automatically generate photogrammetric point clouds for trees across a range of sizes and species. Estimates of diameters at varying heights were derived from the point clouds and used as inputs to estimation of taper and volume. The accuracy of DTPderived estimates was assessed based on field-measured taper from felled trees and compared with traditional methods (based on height-diameter allometries) for estimation of taper and tree volume.

\section{Materials and methods}

\subsection{Study area}

The study area is a boreal mixedwood forest near the towns of Swan Hills and Slave Lake in Alberta, Canada. The study area ranges from approximately $54.97-55.26^{\circ} \mathrm{N}$ and approximately $115.08-115.58^{\circ} \mathrm{W}$. The 700,000 -ha forest management area is primarily used for timber harvesting 
and oil and gas extraction. Ten tree species are present, with the most common being white spruce (Picea glauca), black spruce (Picea mariana), trembling aspen (Populus tremuloides), and lodgepole pine (Pinus contorta). The region receives approximately $600 \mathrm{~mm}$ of annual precipitation and has mean summer and winter temperatures of $20{ }^{\circ} \mathrm{C}$ and -21 ${ }^{\circ} \mathrm{C}$, respectively (Natural Regions Committee 2006). Elevation in the study area ranges from 545 to $1575 \mathrm{~m}$ above sea level.

\subsection{Field data}

The trees measured in this study were located within plots established in July 2018. Field plots were part of a systematic random sample capturing the height and species ranges of stands present. Within plots, trees $\geq$ $7 \mathrm{~cm} \mathrm{DBH}$ were measured, including species, height, height to live crown, crown class, and DBH. Across the ten sample plots, 15 individual trees were randomly selected and photographed as outlined in Section 2.3. Trees were later felled, and diameters were measured in $1-\mathrm{m}$ increments up the stem. Field-measured volume was calculated as the sum of sections in between diameter measurements up each stem. Attributes for each tree are shown in Table 1.

Table 1 Characteristics of trees $(n=15)$ used in this study. Species codes are as follows: Aw trembling aspen (Populus tremuloides), $S w$ white spruce (Picea glauca), Pl lodgepole pine (Pinus contorta latifolia), Bw paper birch (Betula papyrifera), Sb black spruce (Picea mariana), $\mathrm{Fb}$ balsam fir (Abies balsamea)

\begin{tabular}{lllll}
\hline Tree ID & Species & Height $(\mathrm{m})$ & DBH $(\mathrm{cm})$ & Volume $\left(\mathrm{m}^{3}\right)$ \\
\hline 1 & Aw & 28.6 & 28.6 & 0.9296 \\
2 & Aw & 22.3 & 15.7 & 0.2028 \\
3 & $\mathrm{Sw}$ & 25.9 & 30 & 0.9071 \\
4 & $\mathrm{Sw}$ & 26.3 & 40.4 & 1.696 \\
5 & $\mathrm{Pl}$ & 17.0 & 17.1 & 0.2078 \\
6 & $\mathrm{Sw}$ & 22.2 & 38.1 & 1.140 \\
7 & $\mathrm{Sw}$ & 18.7 & 29.5 & 0.5952 \\
8 & $\mathrm{Pl}$ & 17.0 & 16.1 & 0.1689 \\
9 & $\mathrm{Pl}$ & 26.2 & 26.4 & 0.7626 \\
10 & $\mathrm{Pl}$ & 18.2 & 15 & 0.1962 \\
11 & $\mathrm{Sb}$ & 18.0 & 20.7 & 0.3487 \\
12 & $\mathrm{Pl}$ & 19.8 & 26.1 & 0.5437 \\
13 & $\mathrm{Sb}$ & 21.8 & 31 & 0.7288 \\
14 & $\mathrm{Sb}$ & 9.70 & 10.8 & 0.0525 \\
15 & $\mathrm{Fb}$ & 26.0 & 25.5 & 0.6668 \\
Mean & - & 21.18 & 24.73 & 0.6098 \\
\hline
\end{tabular}

\subsection{Image acquisition}

Before images were taken, five coded targets were positioned on and around the tree (four on the ground and one on a tree approximately $2 \mathrm{~m}$ high). In some cases, targets were placed on the selected tree but were filtered from resulting point clouds. Targets were generated by Agisoft Photoscan (Agisoft 2018) for automatic detection during image matching, and each target took up approximately the width of a standard letter-sized page $(22 \times 28 \mathrm{~cm})$. The targets were used to enhance image alignment, both within and between image locations.

Figure 1 details the image acquisition method. Images were acquired using two RICOH Theta S (RICOH 2017) cameras mounted on a telescoping pole. Each camera is equipped with two fisheye lenses whose images are stitched together to generate a single spherical image with a $360^{\circ}$ field of view. The mount ensured the two cameras remained at a fixed distance apart $(70.0 \mathrm{~cm})$, which allowed this distance to be input as a scale bar during point cloud processing, outlined in Section 2.4. Sets of simultaneous images, acquired with both cameras, were taken at each of three heights, approximately 2 , 3 , and $5 \mathrm{~m}$ above the ground, and at each of two locations around the tree. The result was a set of 12 images (two cameras, three heights above the ground, two locations). Using two adjacent cameras (placed $\sim 70 \mathrm{~cm}$ from each other) allowed for high (close to 100\%) overlap between image pairs. Sets of images taken at two locations meant that approximately half of the circumference of the tree was visible in the set of images. Preliminary testing showed that this methodology provided sufficient coverage around the tree for circlefitting techniques to accurately estimate stem diameter. The locations of camera positions and coded targets were recorded relative to ground level at the location of the first image set, which was set as a center of a local coordinate system (with xyz coordinates of $0,0,0$ ). Table 2 compares the methodology presented in this study to that of previous work producing photogrammetric point clouds from ground-based images.

\subsection{Point cloud generation}

Point clouds were processed using an automated Agisoft Photoscan workflow (Agisoft 2018). First, camera and target locations were entered and targets were automatically detected. Next, a scale bar between each set of photographs was set as the distance between the images taken in the field $(\sim 70$ $\mathrm{cm}$ ). Photos were aligned using a "high" setting, and the resulting tie points were filtered to remove those with high reconstruction uncertainty. Finally, dense point clouds were generated using a "high" setting and were then exported to be used in further processing. Processing was performed on a computer with an Intel Xenon E5-2630 (24 cores @ $2.3 \mathrm{GHz}$ ), 64 GB of DDR3 RAM, and an NVIDIA Quadro P4000 GPU. 
a

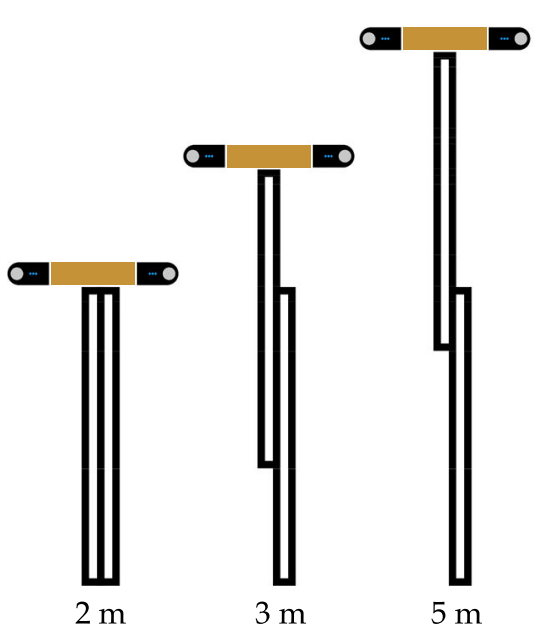

$\mathrm{b}$

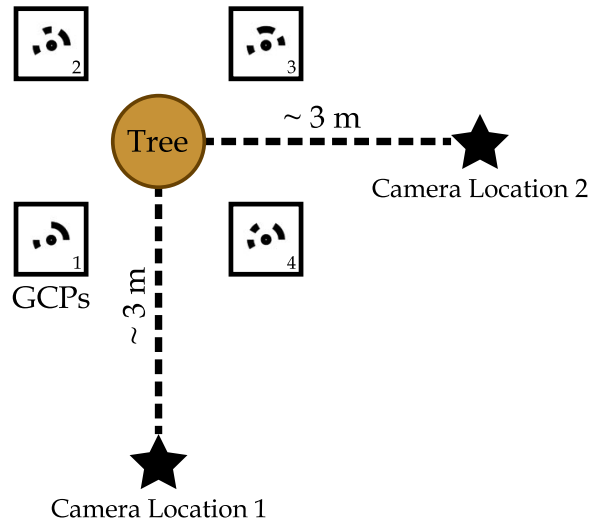

C

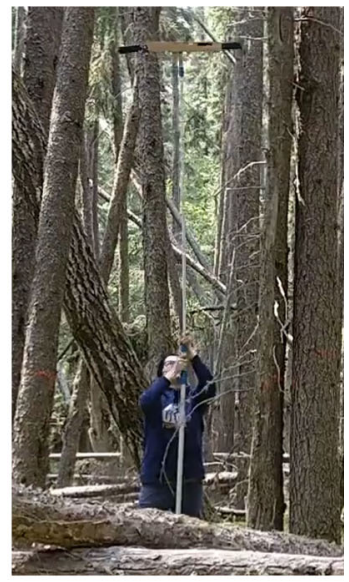

Fig. 1 Image acquisition methodology used in this study. a Outlines of the camera mount setup. b Details of the approximate location of photos and coded targets (GCPs) in relation to the tree. $\mathbf{c}$ The camera in use during field acquisition

\subsection{Attribute extraction}

Generated point clouds were analyzed in Computree (Piboule et al. 2015), a collaborative and open-source software to derive detailed tree-level estimates from ground-based point clouds. Analysis followed a standard Computree workflow, beginning with detection and removal of ground points, followed by noise removal (Belton et al. 2013). In the next step, horizontal clustering of points and vertical aggregation into logs was performed. For resulting logs, cylinders were fit at various heights up the stem using a least squares fitting technique (e.g., Berveglieri et al. 2017). Finally, smoothed diameters were calculated at breast height and 1-m intervals by averaging diameters of neighboring cylinders (e.g., 1.2-1.4 $\mathrm{m}$ for $\mathrm{DBH})$.

\subsection{Taper and volume assessment}

As heights of the point cloud measurements did not reach the full height of the stem, estimates of taper were determined by matching point cloud-derived diameters to a database of all possible taper curves for the area. In Alberta, variableexponent taper equations are used (Kozak 1988), and parameters of these curves are adapted to various ecoregions of the province (Huang 1994). Generation of the curve database and associated matching techniques are described below.

\subsubsection{Curve database}

Taper curves were generated for all possible tree dimensions in the study area based on parameters used throughout the province (Huang 1994). To generate each curve, taper equations required inputs of species, ecoregion, $\mathrm{DBH}$, and total height, while outputting the diameter of the tree at any given height. All possible taper curves were thereby created using all possible combinations of the variables in our study area - all three ecoregions, six species, DBH values from 4 to $40 \mathrm{~cm}$ in $0.1-\mathrm{cm}$ increments, and height values from 5 to $35 \mathrm{~m}$, in $0.1-\mathrm{m}$ increments. For each combination, equations output the diameter values at height increments of $10 \mathrm{~cm}$ up the stem. The list of curves was then filtered to remove trees whose allometries were unlikely to exist in our study area (e.g., trees that were $30 \mathrm{~m}$ tall and had a $4 \mathrm{~cm}$ DBH), by removing curves from the database whose height values were not within $\pm 5 \mathrm{~m}$ of the predicted height from the specified allometric equation. This limited the database to allometrically valid taper curves (e.g., those that could exist in the study area) and resulted in a final database of 1,652,778 taper curves.

\subsubsection{Curve matching}

Point cloud measurements of diameter at different vertical heights were used to match to possible taper curves. Two different curve matching approaches were evaluated in this study, outlined in Fig. 2. In the first method (1), diameters were not weighted and the curve chosen based on having the smallest residual between the point cloud-derived diameters and diameters from possible taper curves. The second method (2) applied weighting factors to the residuals of diameters closest to $3.28 \mathrm{~m}$. This $3.28 \mathrm{~m}$ height was chosen as it was the average of the three camera heights, and all cameras are expected to have the lowest residual distance to this point on the stem, potentially making it the portion of the stem most accurately reconstructed by the point clouds. 


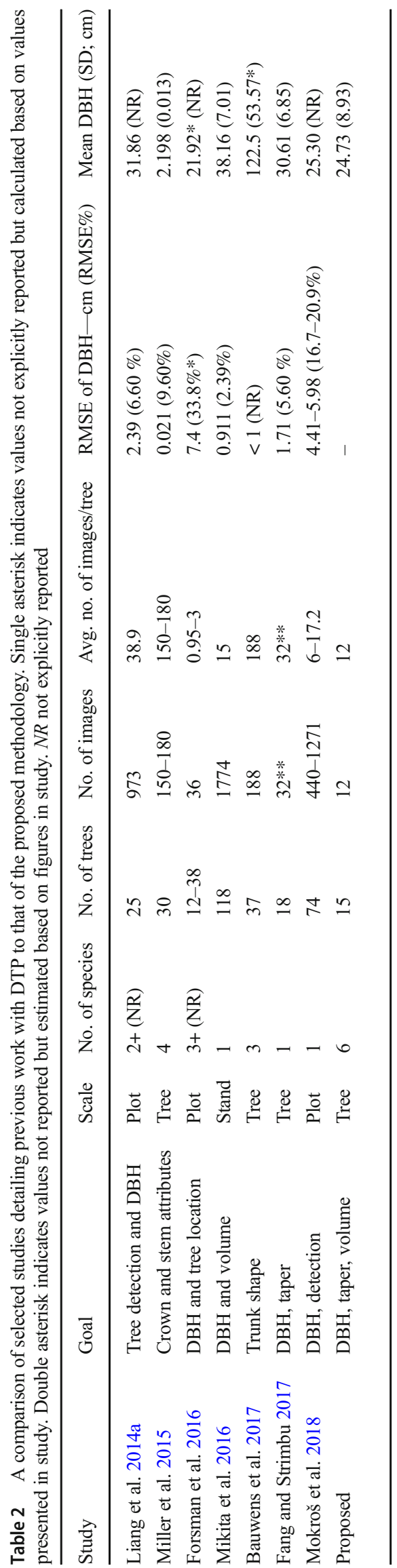

\subsubsection{Verification and accuracy assessment}

As a comparison, estimates from the point cloud curve matching were compared with three other methods: (3) the selection of a taper curve based on measured DBH, height (from laser hypsometer), and species before trees were felled; (4) field-measured DBH and species were used as inputs to height-diameter allometric equations (Huang 1994) to predict a tree height, which was then input to select a taper curve; (5) the fifth dataset was similar to the fourth, but used DBH as estimated from the point cloud as an input to a height-diameter equation to predict height. In summary, five methods were compared, two of which used field measurements to match a taper equation (3 and 4), and three which were based on point cloud estimates of diameter (1,2, and 5). An overview of these methods is shown in Fig. 3. The accuracies of the DBH, volume, and taper were evaluated by using the root-meansquared error (RMSE), RMSE relative to the mean (RMSE\%), bias, and bias relative to the mean (bias\%). Results of the methods were tested to see if estimates differed significantly from one another using a $t$ test. The equations for these statistics are as follows:

$R M S E=\sqrt{\frac{1}{N} \sum_{i=1}^{N}\left(\hat{y}_{i}-y_{i}\right)^{2}}$,

$R M S E \%=\frac{R M S E}{\bar{y}} \times 100$

$\operatorname{bias}=\frac{1}{N} \sum_{i=1}^{N}\left(\hat{y}_{i}-y_{i}\right)$

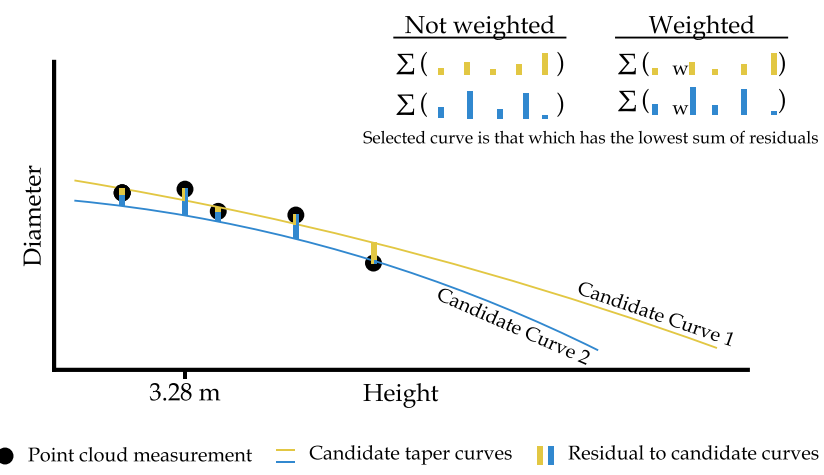

Fig. 2 A representation of the two different curve matching techniques (not weighted and weighted) used in this study. $w$ in the equations indicates the weight applied to the residual closest to $3.28 \mathrm{~m}$. In this simplified example, the blue and yellow lines represent two candidate curves coming from the generated taper curve database. In the curve database, however, there were approximately 90,000 candidate curves for each species in each ecoregion 


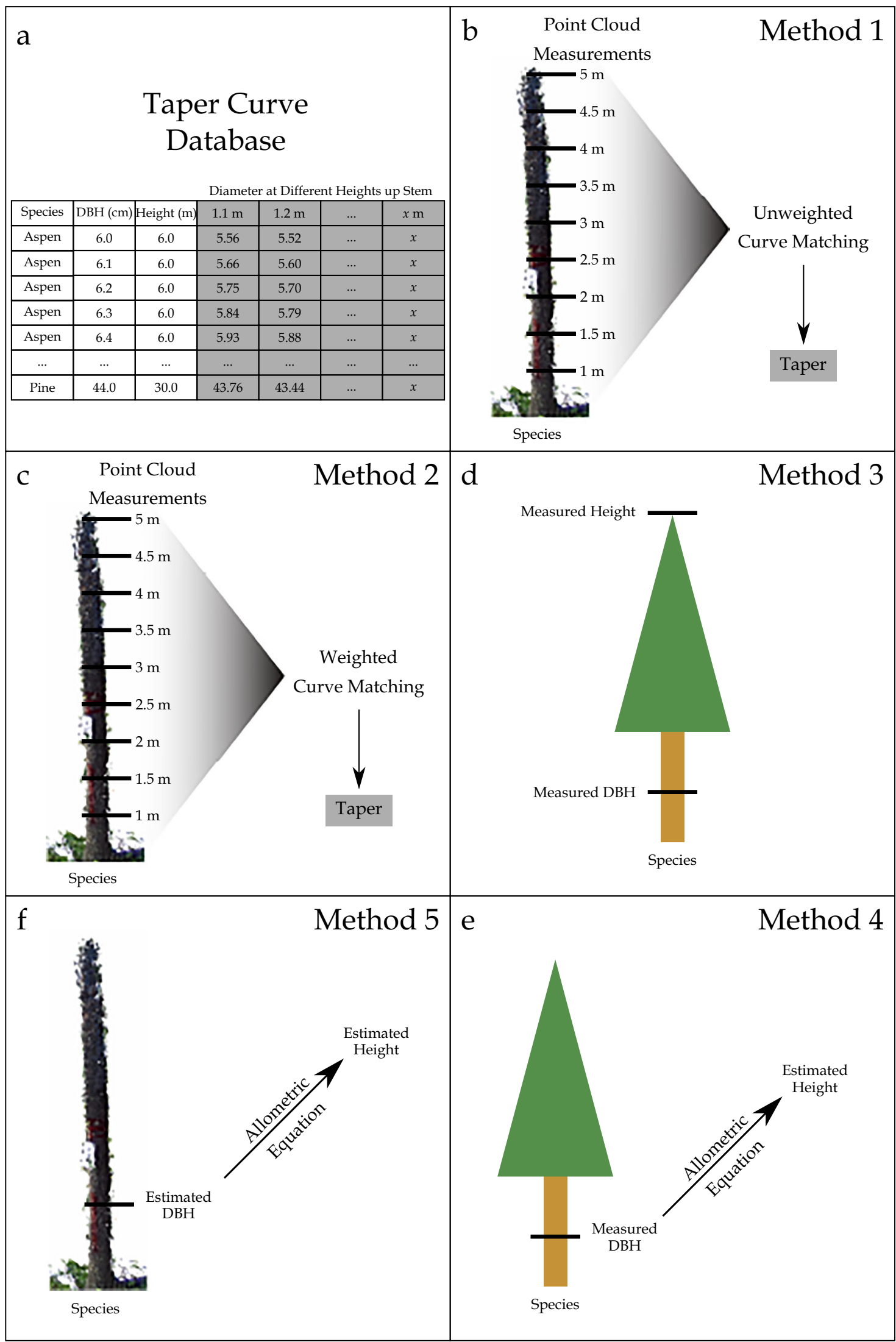

Fig. 3 An overview of the five methods used: curve matching (b-c.; methods 1 and 2), inputting field measurements (d-e.; methods 3 and 4 ), and using the DBH as estimated from the point clouds (f.; method 5) 
$\operatorname{bias} \%=\frac{\text { bias }}{\bar{y}} \times 1$,

where $N$ is the number of trees, $y_{i}$ is the reference measurement for tree $i, \hat{y}_{i}$ is the predicted measurement for tree $i$, and $\bar{y}$ is the mean of reference measurements on all trees.

\section{Results}

\subsection{Point cloud reconstruction and diameter estimates}

Once an efficient processing workflow was produced, the total amount of time taken for all steps was, on average, $8 \mathrm{~min}$ per tree $(3 \mathrm{~min}$ for setup of locations and targets, 1 min for image acquisition, 3.5 min for point cloud generation, $0.25 \mathrm{~min}$ for deriving measurements from Computree, and $0.25 \mathrm{~min}$ for curve matching). The resulting point clouds contained between 10,000 and 62,000 stem points for the shortest (tree 14) and tallest (tree 1) trees, respectively. Points covered an area immediately around the stem and ranged from ground level to a maximum height of 4 to $8 \mathrm{~m}$. Diameter estimates were derived from DTP point clouds, shown in Figs. 4 and 5, and showed good, unbiased correspondence with manual measurements (1.28 cm RMSE, 5.15 RMSE\% for DBH). This degree of correspondence was observed at other heights along the stem, although the DTP-derived point clouds rarely allowed extraction of diameter

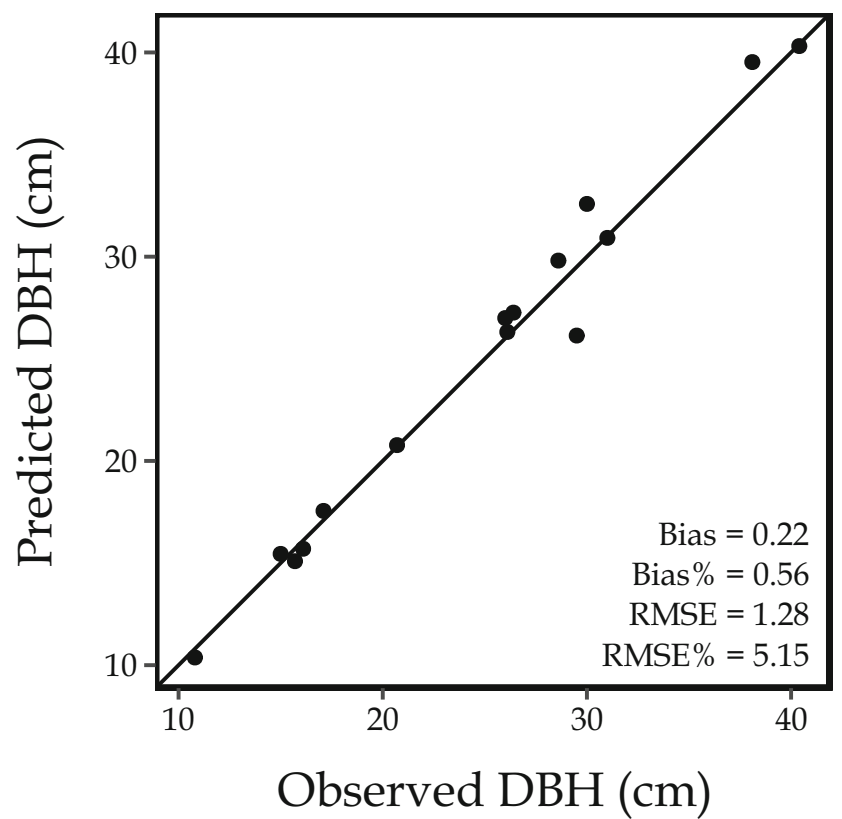

Fig. 4 Comparison between observed and predicted DBH measurements $(n=15)$ from DTP point clouds measurements above $5 \mathrm{~m}$. For example, for one of the tallest measured trees (tree 9, a large lodgepole pine, $26.4 \mathrm{~cm}$ DBH, $26.2 \mathrm{~m}$ height; Table 1), the generated point cloud allowed stem reconstruction up to $9 \mathrm{~m}$ above the ground. The shortest stem reconstruction was to a height of $3.5 \mathrm{~m}$ on a small black spruce (tree 14, $10.8 \mathrm{~cm} \mathrm{DBH}, 9.7 \mathrm{~m}$ height). In general, lower stem heights (e.g., $<3 \mathrm{~m}$ ) had approximately $50 \%$ of the circumference of the tree represented by points. However, point clouds further up the stem generally became more obscured by canopy or branches, resulting in less direct observation by some of the camera perspectives. This resulted in approximately $25 \%$ of the stem circumference being represented by points. Despite this, points coming from one camera location were often enough to derive a sufficiently accurate diameter estimate. For example, a separate analysis using only six images at a single location for point cloud reconstruction yielded an RMSE of $2.00 \mathrm{~cm}$, or $8.10 \%$, for DBH estimation.

\subsection{Upper stem diameters and taper assessment}

The relationship between measured and predicted stem diameters for all trees and all evaluation methods is shown in Fig. 5. For comparison across trees of different heights, the relationship is shown as both the measurement error by absolute height up the stem and the percentage of total tree height for individual trees. For diameters at lower sections of the stem $(<8 \mathrm{~m})$, both curve matching techniques (methods 1 and 2) performed better than other approaches ( $\sim 0.5 \mathrm{~cm}$ RMSE). Above $10 \mathrm{~m}$, or approximately $30 \%$ of total tree height (across stems), method 3 (using the field-measured DBH and height) yielded the most accurate diameter estimates ( $<1 \mathrm{~cm}$ RMSE). In some cases, either the curve matching or an allometric equation yielded inaccurate estimates of total tree height, producing larger discrepancies at upper parts of stems ( $>75 \%$ of total tree height). Despite this, all methods were generally successful at characterizing stem diameter, with the most accurate measurements coming at points in the bottom $13 \mathrm{~m}$ or $50 \%$ of the stem $(<1.5 \mathrm{~cm}$ RMSE).

\subsection{Volume predictions}

The relationship between measured and predicted volumes for the different approaches is shown in Fig. 6. Method 3 (using the field-measured DBH and height) produced the most accurate overall predictions of volume $\left(0.094 \mathrm{~m}^{3}\right.$ RMSE, 15.5 RMSE\%). Independent-samples $t$ tests were conducted to compare mean diameter accuracy for all techniques. For all techniques, there was no significant difference in the mean accuracy of diameters, suggesting that no one technique performed better or worse than the others. All methods of volume 
Fig. 5 Error (RMSE) of diameter estimates at various heights up the stem, with points indicating RMSE at each measured height and lines showing trend generated by smoothed conditional means. Different colored points and lines refer to the five different estimation approaches. The graph on the left shows the error in terms of the absolute height, while the one on the right shows the error at heights relative to the total tree height in $10 \%$ increments. Values over $100 \%$ on the $y$-axis in the right graph indicate an incorrect estimate of total tree height

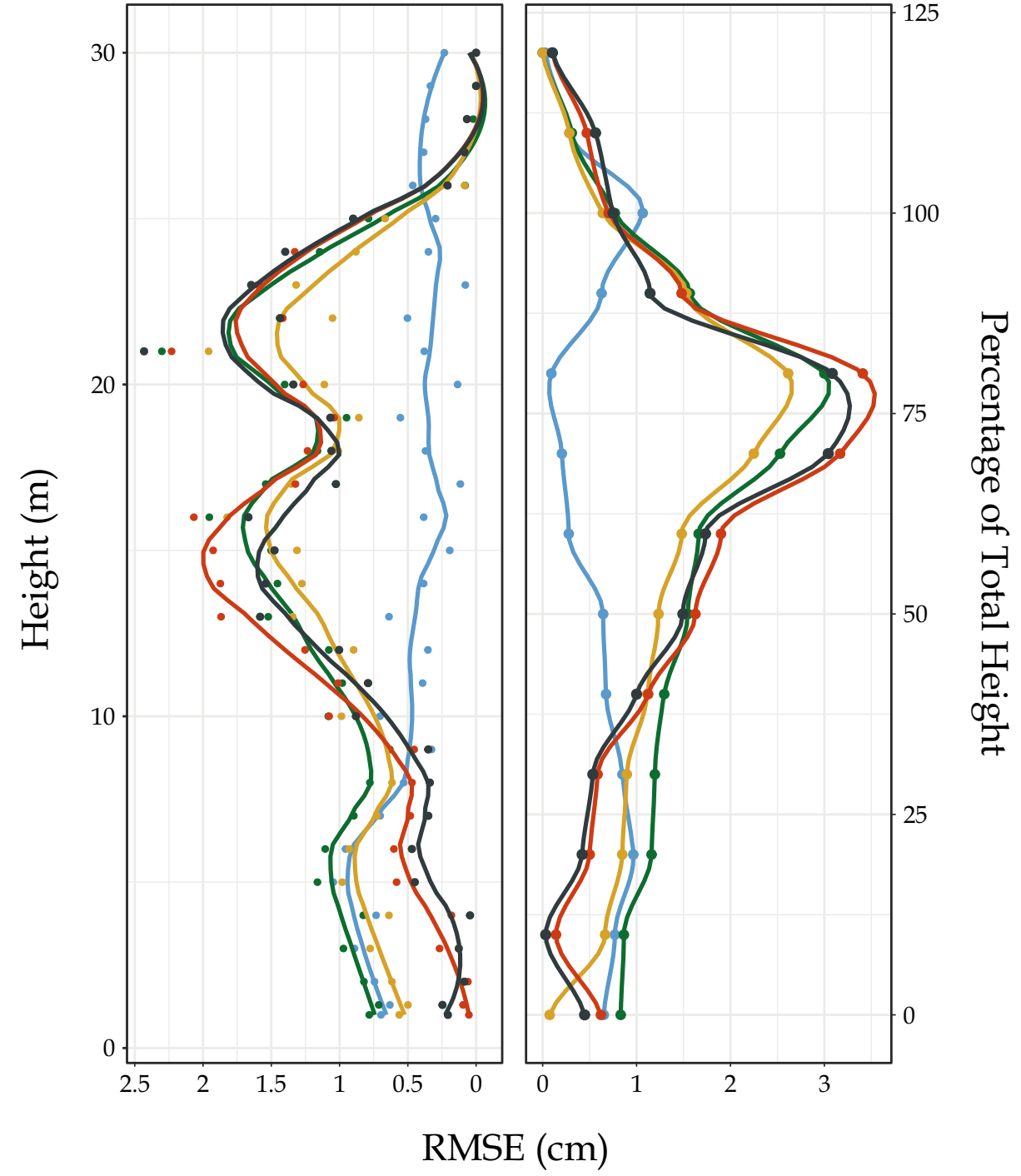

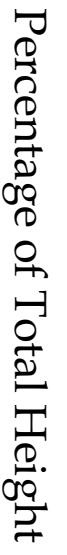

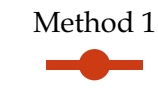

Curve Matching Unweighted

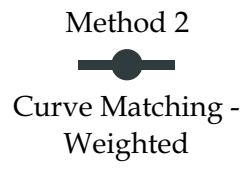

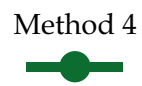

Known DBH
Method 5

Known DBH and Height redicted DBH calculation were slightly negatively biased compared with the ground-measured reference. Of the point cloud-based approaches, method 5 (the predicted DBH and allometrically assigned height) yielded the most accurate estimates (0.099 $\mathrm{m}^{3}$ RMSE, 16.3 RMSE\%), but this was only marginally better and not statistically different than the curve matching approaches (methods 1 and 2). Method 1 (unweighted curve matching) produced more accurate volume estimates $(0.110$ $\mathrm{m}^{3}$ RMSE, 18.1 RMSE\%) than method 2 (weighted curve matching; $0.120 \mathrm{~m}^{3}$ RMSE, 19.6 RMSE\%), indicating that this may be the better of the two curve matching methods. However, for all 15 trees, no method performed significantly better or worse than the others.

\section{Discussion}

\subsection{Diameter estimates}

Stem diameters at multiple heights were extracted from DTP point clouds. Point clouds produced accurate estimates of DBH (Fig. 4), showing a RMSE of $1.28 \mathrm{~cm}$ and a RMSE\% of 5.15 . Point cloud-based curve matching approaches (methods 1 and 2) produced the most accurate measurements for the lowest 8 $\mathrm{m}$, or approximately $30 \%$ of the stem, while using a known DBH and height, method 3 was the most accurate method for the highest parts of the stem. For trees with irregular allometries, it was possible that the taper models used in this study 
inaccurately characterized the diameter at different parts of the stem. However, the models were determined to be generally accurate in their characterization of stem taper. In some cases, methods $1,2,4$, and 5 produced inaccurate estimates of total tree height resulting in inaccurate predictions for volumes and upper stem diameters. This resulted in higher RMSE values for upper parts of trees ( $>50 \%$ of total height) in scenarios where the total height was unknown. However, most tree height estimates were within $3 \mathrm{~m}$ of the true height (after falling), and all methods produced RMSEs of less than approximately $1.5 \mathrm{~cm}$ for the lowest $50 \%$ of the stem. Most tree heights measured in the field by a laser hypsometer were within $1 \mathrm{~m}$ of the true height (after falling), but deviated by about $3 \mathrm{~m}$ for the tallest two trees. These discrepancies between field-measured (hypsometer) and observed tree height are consistent with findings from Luoma et al. (2017), who determined that the standard deviation of field-measured height was $0.5 \mathrm{~m}$ (2.9\%), up to a maximum of $4.2 \mathrm{~m}$.

When compared with other studies estimating individual tree DBH from DTP point clouds (Miller et al. 2015; Bauwens et al. 2017; Fang and Strimbu 2017), we used fewer photographs (12) and evaluated more species (6) while achieving similar levels of accuracy (Table 2). For example, Fang and Strimbu (2017) reported DBH estimates with an
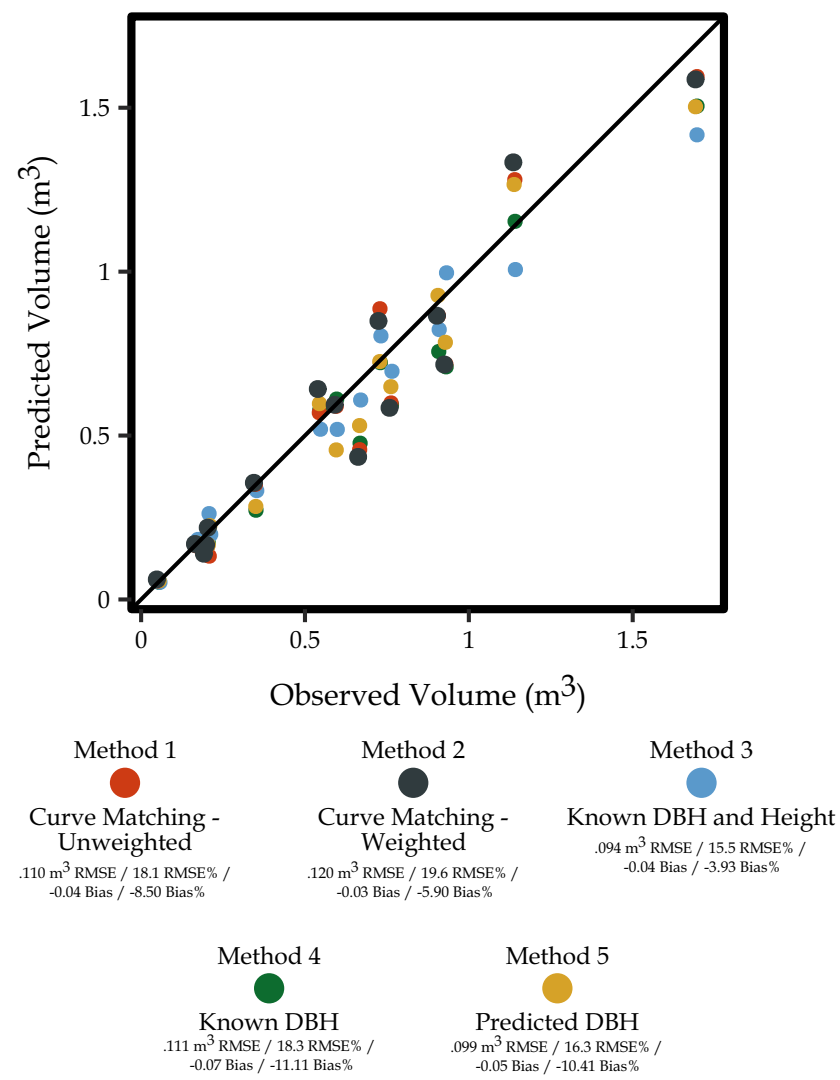

Fig. 6 The accuracies of the five different methods for volume estimation. Each point represents a tree and is colored according to the method presented
RMSE\% of 5 in a monospecific plantation. Our similar accuracy with six species indicates that there may not be a strong correlation between tree species and DBH accuracy; however, small sample sizes in both studies may not be sufficiently large to make this determination.

Our achieved accuracy with a relatively low number of images may have resulted from the inclusion of six scale bars (i.e., one between each set of adjacent images at three different heights), which was set to the distance between the cameras as they were mounted on the pole. This allowed the point clouds to be scaled more accurately than using the target locations alone. Forsman et al. (2016) also used a camera rig (multiple cameras mounted to a portable device) to scale the images with known distances while using an average of less than three images per tree to detect and measure stems on sample plots. Therefore, a rig-based system with known distances between cameras may be instrumental in producing accurate estimates of tree dimensions in cases where relatively few images per tree are captured.

\subsection{Volume assessment}

Photogrammetric point clouds were generally accurate in estimating tree volume. For smaller trees (i.e., under $0.5 \mathrm{~m}^{3}$ ), all methods of volume estimation produced similar accuracies. For the largest two trees, method 3 (using the field-measured $\mathrm{DBH}$ and height) produced inaccurate estimates, possibly due to inaccurate height measurements as taken from the ground, which has been shown to be influenced by stand conditions, crown class, and tree species (Wang et al. 2019). Although more accurate diameter measurements at upper parts of the stem came from method 3 (field-measured DBH and height), the majority of a tree's volume is in the lowest portions of the stem, indicating that accurate diameter measurements at the bottom - possibly coming from DTP point clouds - could also result in more accurate volume estimates. For example, the lower $50 \%$ of tree stems in our study contained about $80 \%$ of the total tree's volume.

Results from this study described the ability of $360^{\circ}$ cameras to derive detailed tree-level measurements. The cameras' large field of view means that resulting point clouds have a larger coverage area than traditional frame cameras, which are typically employed during field operations. This outlines the potential of the $360^{\circ}$ cameras to characterize larger areas such as sample plots or stands, as larger coverage from individual images would result in fewer images being required for point cloud generation. As a comparison, the frame cameras used in Liang et al. (2014a) and Mokroš et al. (2018) were able to successfully characterize DBH for trees on sample plots, but used up to 973 and 1271 images for 900 and $1225-\mathrm{m}^{2}$ plots, respectively. Spherical images could also provide the basis for a combination of terrestrial and aerial photogrammetric point clouds, such as in Mikita et al. (2016), who used terrestrial and 
aerial images to characterize tree DBHs and volumes in a 0.8ha stand. For individual trees, however, only a subset of the entire $360^{\circ}$ field of view was used for tree reconstruction, indicating that similar accuracies may be achieved using a rig-based system of wide-angle or fisheye lens cameras.

Of the related studies listed in Table 2, only one estimated volume from DTP point clouds (Mikita et al. 2016). Volume estimates from point clouds in their study $\left(0.082 \mathrm{~m}^{3}\right)$ were slightly more accurate than those reported here $\left(0.099 \mathrm{~m}^{3}\right)$. In this study, we evaluated the ability to derive individual tree characteristics based on point clouds created from fewer images and tested on more species than presented in Mikita et al. (2016). Additionally, Mikita et al. (2016) combined DTP and DAP point clouds, while our study was limited to ground-based images. More study is needed to determine the relationships, if any, between point cloud accuracy and characteristics such as tree size, branchiness, species, or stem density of the surrounding area. Based on an international benchmarking study of TLS by Liang et al. (2018), stem detection rates decreased with decreasing mean DBHs and stem density, while DBH estimates were stable across stand conditions. Smaller trees will have less surface area for point cloud reconstruction, meaning that there may be a resulting increase in error of DBH estimation with decreasing tree size (Ryding et al. 2015).

\subsection{Applications}

When compared with DTP, TLS provides more comprehensive point clouds that can be used for more detailed study such as wood quality and has the ability to return points from occluded areas such as in stands with a high stem density or on stems with many branches. However, the results seen in this study indicate the potential for DTP to provide similar levels of accuracy to TLS in DBH and volume estimates. Studies using a single TLS scan reported 1-3 cm RMSE for DBH (Maas et al. 2008; Liang and Hyyppä 2013) and $~ 10$ RMSE\% for volume (Liang et al. 2014b), similar to the results reported here. Liang et al. (2018) also reported accuracies of 10 and 20 RMSE\% for "easy" (low stem density and high mean DBH) and "difficult" (high stem density and low mean DBH) plots, respectively. The accuracies attained in this study indicate the potential for DTP for supporting forest inventories. National Forest Inventories (NFIs) have typical accuracy requirements of $0-2 \mathrm{~cm}$ for $\mathrm{DBH}, 10-20 \%$ for volume, and 1$3 \mathrm{~cm}$ for upper stem diameters (Liang et al. 2016). Each of these accuracy requirements was met using DTP point clouds techniques in this study. Other potential applications of raw images and resulting point clouds include the estimation of canopy leaf area (Bréda 2003) or as inputs to centroid sampling of tree volume (Wiant et al. 1992).

Additionally, point clouds provide measurements which can be stored as an objective, 3D snapshot of a tree or forest condition at a given point in time. This indicates potential for the use of DTP in calibrating or validating models of forest growth. If images of the same tree are acquired at multiple times, a time series of point clouds could be generated and analyzed to monitor tree growth or change either at an individual tree or at stand level (Sheppard et al. 2016; Liang et al. 2012). Should allometric or taper models not exist, be inaccurate, or require update, point clouds could provide reference data to validation or parameterization of such models.

While TLS provides attributes such as branching structure and direct measurements of upper stem diameters, the cost of handheld cameras is in the hundreds of dollars, far less than TLS units, which can be two orders of magnitude higher. Although the focus of this study was on the structural qualities of the point clouds, their spectral attributes could be used, similar to aerial images, to assess species compositions (e.g., Packalen and Maltamo 2006) and tree condition or quality (e.g., Goodbody et al. 2018). Overall, the low cost and portability of the cameras, in addition to the objectivity and storability of the point clouds, show their value as a tool in forest inventory and modeling.

\section{Conclusion}

Changing resource demands and climatic conditions require quick and inexpensive means of deriving robust and accurate forest inventory measurements. DTP is one such tool that could be used to enhance traditional forest inventories. This study showed that DTP is able to produce sufficiently accurate estimates of volume and diameter that generally only slightly differed from traditional inventory techniques. The inclusion of fixed scale bars between known camera locations was critical in deriving accurate measurements from resulting point clouds. Using this methodology, accurate point clouds were produced for a variety of tree species and sizes, demonstrating the possibility of using such a technology at larger scales as well as the utility of DTP in characterizing trees present in complex and changing habitats such as the boreal mixedwood forests.

Acknowledgments We thank the staff at Alberta Agriculture and Forestry for their input and assistance with the fieldwork.

Funding This research was funded by the AWARE (Assessment of Wood Attributes using Remote Sensing) Natural Sciences and Engineering Research Council of Canada Collaborative Research and Development grant (NSERC File: CRDPJ 462973-14) to a team led by Nicholas Coops with support from West Fraser Timber Co. Ltd. Additional funding for field data collection was provided by Alberta Agriculture and Forestry and West Fraser Timber Co. Ltd.

Data availability An example point cloud showing DTP reconstruction of tree 11 can be found in the ResearchGate repository (Mulverhill et al. 2019) at https://doi.org/10.13140/RG.2.2.23986.86725. Additionally, a web viewer showing this tree can be found at http://irss-pov.forestry.ubc. ca/tree_11.html 


\section{Compliance with ethical standards}

Conflict of interest The authors declare that they have no conflict of interest.

Open Access This article is distributed under the terms of the Creative Commons Attribution 4.0 International License (http:// creativecommons.org/licenses/by/4.0/), which permits unrestricted use, distribution, and reproduction in any medium, provided you give appropriate credit to the original author(s) and the source, provide a link to the Creative Commons license, and indicate if changes were made.

\section{References}

Agisoft LLC (2018) Agisoft Photoscan Professional Edition. Version 1.4.3. Retrieved from http://www.agisoft.com/downloads/installer/. Accessed 10 Aug 2018

Bahamondez C, Álvarez O, Itzelcoaut M (2010) Global Forest Resources Assessment 2010: Main Report. Food and Agriculture Organization of the United Nations (FAO). http://www.fao.org/forestry/fra/ fra2010. Accessed 10 Jan 2019

Bauwens S, Fayolle A, Gourlet-Fleury S, Ndjele LM, Mengal C, Lejeune P (2017) Terrestrial photogrammetry: a non-destructive method for modelling irregularly shaped tropical tree trunks. Methods Ecol Evol 8(4):460-471. https://doi.org/10.1111/2041-210X.12670

Belton D, Moncrieff S, Chapman J (2013) Processing tree point clouds using Gaussian mixture models. In: Proceedings of the ISPRS Annals of the Photogrammetry. Remote Sensing and Spatial Information Sciences 43-48. Antalya: ISPRS. https://doi.org/10. 5194/isprsannals-II-5-W2-43-2013

Berveglieri A, Oliveira RO, Tommaselli AMG (2014) A feasibility study on the measurement of tree trunks in forests using multi-scale vertical images. Int Arch Photogramm 40(5):87-92. https://doi.org/10. 5194/isprsarchives-XL-5-87-2014

Berveglieri A, Tommaselli A, Liang X, Honkavaara E (2017) Photogrammetric measurement of tree stems from vertical fisheye images. Scand J For Res 32(8):743-747. https://doi.org/10.1080/ 02827581.2016 .1273381

Bréda NJJ (2003) Ground-based measurements of leaf area index: a review of methods, instruments and current controversies. J Exp Bot 54(392):2403-2417. https://doi.org/10.1093/jxb/erg263

Chen HYH, Popadiouk RV (2002) Dynamics of North American boreal mixedwoods. Environ Rev 10(3):137-166. https://doi.org/10.1139/ A02-007

Eitel JUH, Vierling LA, Magney TS (2013) A lightweight, low cost autonomously operating terrestrial laser scanner for quantifying and monitoring ecosystem structural dynamics. Agric For Meteorol 180:86-96. https:// doi.org/10.1016/j.agrformet.2013.05.012

Fang R, Strimbu BM (2017) Stem measurements and taper modeling using photogrammetric point clouds. Remote Sens 9(7):716. https://doi.org/10.3390/rs9070716

Forsman M, Börlin N, Holmgren J, Forsman M, Börlin N, Holmgren J (2016) Estimation of tree stem attributes using terrestrial photogrammetry with a camera rig. Forests 7(12):61. https://doi.org/10.3390/ f7030061

Gillis MD, Omule AY, Brierly T (2005) Monitoring Canada's forests: the National Forest Inventory. For Chron 81(2):214-221. https://doi. org $/ 10.5558 / \mathrm{tfc} 81214-2$

Gobakken T, Næsset E (2004) Estimation of diameter and basal area distributions in coniferous forest by means of airborne laser scanner data. Scand J For Res 19(6):529-542. https://doi.org/10.1080/ 02827580410019454
Goodbody TRH, Coops NC, Hermosilla T, Tompalski P, McCartney G, MacLean DA (2018) Digital aerial photogrammetry for assessing cumulative spruce budworm defoliation and enhancing forest inventories at a landscape-level. ISPRS J Photogramm Remote Sens 142: 1-11. https://doi.org/10.1016/j.isprsiprs.2018.05.012

Hapca AI, Mothe F, Leban J-M (2007) A digital photographic method for 3D reconstruction of standing tree shape. Ann For Sci 64(6):631637. https://doi.org/10.1051/forest:2007041

Hetemäki L, Mery G, Holopainen M, Hyyppä J, Vaario L-M, Yrjälä K (2010) Implications of technological development to forestry. For. Soc. - Responding to Glob. Drivers Chang, IUFRO (International Union of Forestry Research Organizations) Secretariat, Vienna, Austria, pp 157-181

Huang S (1994) Ecologically based individual tree volume estimation for Major Alberta tree species Government of Alberta. Pub. Edmonton

Kozak A (1988) A variable-exponent taper equation. Can J For Res 18(11):1363-1368. https://doi.org/10.1139/x88-213

Lambert M-C, Ung C-H, Raulier F (2005) Canadian national tree aboveground biomass equations. Can J For Res 35(8):1996-2018. https:// doi.org/10.1139/X05-112

Leckie DG, Gillis MD (1995) Forest inventory in Canada with emphasis on map production. For Chron 71(1):74-88

Liang X, Hyyppä J (2013) Automatic stem mapping by merging several terrestrial laser scans at the feature and decision levels. Sensors 13(2):1614-1634. https://doi.org/10.3390/s130201614

Liang X, Hyyppä J, Kaartinen H, Holopainen M, Melkas T (2012) Detecting changes in forest structure over time with bi-temporal terrestrial laser scanning data. ISPRS Int J Geo-Inf 1(3):242-255. https://doi.org/10.3390/ijgi1030242

Liang X, Jaakkola A, Wang Y, Hyyppä J, Honkavaara E, Liu J, Kaartinen $\mathrm{H}$ (2014a) The use of a hand-held camera for individual tree 3D mapping in forest sample plots. Remote Sens 6:6587-6603. https://doi.org/10.3390/rs6076587

Liang X, Kankare V, Xiaowei Y, Hyyppa J, Holopainen M (2014b) Automated stem curve measurement using terrestrial laser scanning. IEEE Trans Geosci Remote Sens 52(3):1739-1748. https://doi.org/ 10.1109/TGRS.2013.2253783

Liang X, Kankare V, Hyyppä J, Wang Y, Kukko A, Haggrén H, Yu X, Kaartinen H, Jaakkola A, Guan F, Holopainen M, Vastaranta M (2016) Terrestrial laser scanning in forest inventories. ISPRS J Photogramm Remote Sens 115:63-77. https://doi.org/10.1016/j. isprsjprs.2016.01.006

Liang X, Hyyppä J, Kaartinen H, Lehtomäki M, Pyörälä J, Pfeifer N, Holopainen M, Brolly G, Francesco P, Hackenberg J, Huang H, Jo HW, Katoh M, Liu L, Mokroš M, Morel J, Olofsson K, Poveda-Lopez J, Trochta J, Wang D, Wang J, Xi Z, Yang B, Zheng G, Kankare V, Luoma V, Yu X, Chen L, Vastaranta M, Saarinen N, Wang Y (2018) International benchmarking of terrestrial laser scanning approaches for forest inventories. ISPRS J Photogramm Remote Sens 144(June):137179. https://doi.org/10.1016/j.isprsjprs.2018.06.021

Luoma V, Saarinen N, Wulder M, White J, Vastaranta M, Holopainen M, Hyyppä $J$ et al (2017) Assessing precision in conventional field measurements of Individual Tree Attributes. Forests 8(2):38. https://doi.org/10.3390/f8020038

Maas HG, Bienert A, Scheller S, Keane E (2008) Automatic forest inventory parameter determination from terrestrial laser scanner data. Int J Remote Sens 29(5):1579-1593. https://doi.org/10.1080/ 01431160701736406

Mikita T, Janata P, Surovỳ P (2016) Forest stand inventory based on combined aerial and terrestrial close-range photogrammetry. Forests 7(8):1-14. https://doi.org/10.3390/f7080165

Miller J, Morgenroth J, Gomez C (2015) 3D modelling of individual trees using a handheld camera: accuracy of height, diameter and volume estimates. Urban For Urban Green 14(4):932-940. https://doi.org/ 10.1016/J.UFUG.2015.09.001 
Mokroš M, Liang X, Surový P, Valent P, Čerňava J, Chudý F, Tunák D, Saloň Š, Merganič J (2018) Evaluation of close-range photogrammetry image collection methods for estimating tree diameters. ISPRS Int J Geo-Inf 7(3):93. https://doi.org/10.3390/ijgi7030093

Mulverhill C, Coops NC, Tompalski P, Bater CW, Dick AR (2019) Terrestrial photogrammetric reconstruction of black spruce (Picea mariana) tree. Version May 2019. ResearchGate. [Dataset]. https:// doi.org/10.13140/RG.2.2.23986.86725

Natural Regions Committee (2006) Natural regions and subregions of Alberta. Compiled by DJ Downing and WW Pettapiece. Government of Alberta. Pub

Nduwayezu JB, Mafoko GJ, Mojeremane W, Mhaladi LO (2015) Vanishing multipurpose indigenous trees in Chobe and Kasane forest reserves of Botswana. Resour Environ 5(5):167-172. https://doi. org/10.5923/j.re.20150505.05

Packalen P, Maltamo M (2006) Predicting the Plot Volume by Tree Species Using airborne laser scanning and aerial photographs. For Sci 52(6):611-622

Piboule A, Krebs M, Esclatine L, Hervé JC (2015) Computree: a collaborative platform for use of terrestrial LiDAR in dendrometry. In: International IUFRO Conference MeMoWood, 01-04 October 2013 Nancy, France

RICOH (2017) RICOH THETA S. https://theta360.com/en/about/theta/s. html. Accessed 10 Jan 2019

Ryding J, Williams E, Smith M, Eichhorn M (2015) Assessing handheld mobile laser scanners for forest surveys. Remote Sens 7(1):10951111. https://doi.org/10.3390/rs70101095

Sheppard J, Morhart C, Hackenberg J, Spiecker H (2016) Terrestrial laser scanning as a tool for assessing tree growth. IForest 10(1):172

Tao W, Lei Y, Mooney P (2011) Dense point cloud extraction from UAV captured images in forest area. In IEEE International Conference on Spatial Data Mining and Geographical Knowledge Services. Fuzhou. https://doi.org/10.1109/ICSDM.2011.5969071

Taubert F, Hartig F, Dobner H-J, Huth A (2013) "On the challenge of fitting tree size distributions in ecology.” Edited by James P. Brody.
PLoS ONE 8(2):e58036. https://doi.org/10.1371/journal.pone. 0058036

Wang Y, Lehtomäki M, Liang X, Pyörälä J, Kukko A, Jaakkola A, Liu J, Feng Z, Chen R, Hyyppä J (2019) Is field-measured tree height as reliable as believed - a comparison study of tree height estimates from field measurement, airborne laser scanning and terrestrial laser scanning in a boreal forest. ISPRS J Photogramm Remote Sens 147(January): 132-145. https://doi.org/10.1016/J.ISPRSJPRS.2018.11.008

White JC, Stepper C, Tompalski P, Coops N, Wulder M, White JC, Stepper C, Tompalski P, Coops NC, Wulder MA (2015) Comparing ALS and image-based point cloud metrics and modelled forest inventory attributes in a complex coastal forest environment. Forests 6(12):3704-3732. https://doi.org/10.3390/f6103704

White JC, Coops NC, Wulder MA, Vastaranta M, Hilker T, Tompalski P (2016) Remote sensing technologies for enhancing forest inventories: a review. Can J Remote Sens 42(5):619-641. https://doi.org/10. 1080/07038992.2016.1207484

Wiant HV, Wood GB, Gregoire TG (1992) Practical guide for estimating the volume of a standing sample tree using either importance or centroid sampling. For Ecol Manag 49(3-4):333-339. https://doi. org/10.1016/0378-1127(92)90144-X

Wulder MA, Franklin SE, (eds) (2003) Remote sensing of forest environments: concepts and case studies. 1st edn. Springer Science+ Business Media, New York

Wulder MA, Bater CW, Coops NC, Hilker T, White JC (2008) The role of LiDAR in sustainable forest management. For Chron 84(6):807826. https://doi.org/10.5558/tfc84807-6

Publisher's note Springer Nature remains neutral with regard to jurisdictional claims in published maps and institutional affiliations. 